\title{
Egskeiding in die antieke Semitiese wêreld
}

P J W Schutte

Klerksdorp

\begin{abstract}
Divorce in the ancient Semitic world

Although divorces did occur in the ancient Semitic world, divorce never became a casual or even an accepted phenomenon in especially the Jewish community. Marriage was the normal state of affairs for Jews, and they worked hard at maintaining it. This article investigates the issue.
\end{abstract}

\section{INLEIDING}

Alhoewel egskeidingstatistiek die laaste paar jaar die hoogte ingeskiet het in die Westerse samelewings, is dit ' $n$ verskynsel wat so oud is soos die mensdom self. In hierdie studie is daar gepoog om egskeiding by ou Israel en die ander omliggende Semitiese volkere te ondersoek.

\section{OU TESTAMENT}

Wanneer daar na egskeiding in ou Israel gekyk word, is die Ou Testament een van die belangrikste bronne om na te slaan. Dit val mens egter gou op dat daar oor egbreuk meer gesê word as oor egskeiding self. Egbreuk is beskou as 'n sonde wat die aard en wese van die huwelik vernietig het.

\subsection{Egbreuk}

Egbreuk was vernietigend vir 'n huwelik omdat dit die man se alleenreg op seksuele besit van sy vrou geskend het en omdat dit by hom twyfel kon laat ontstaan of sy kinders wel sy eie is (Baab 1982:51). Die wet het egbreuk dan ook ten strengste verbied.

In die tien gebooie staan die verbod op egbreuk tussen dié op moord en diefstal (Eks 20:14; Deut 5:18), Dit lyk of dit hier as 'n oortreding teen die medemens beskou word (Fensham 1984:139). In Levitikus 18:20 word dit as 'n sonde teen die huwelik beskou en volgens Genesis 20:1-13 en 26:7-11 is egbreuk 'n sonde teen God.

In Levitikus 20:10-12 word die doodstraf voorgeskryf vir albei partye wat hulle aan sekere verbode verhoudings skuldig maak, naamlik, egbreuk met die vrou van 'n medeburger, gemeenskap met een van die vader se vroue en gemeenskap met 'n skoondogter. 
In die profetiese boeke, veral in Esegiël, Jeremia en Hosea word egbreuk as 'n metafoor gebruik om die ontrouheid van Israel in haar verhouding met $J H W H$ uit te beeld.

\subsection{Huweliksgebruike}

Voordat daar na egskeiding gekyk kan word, is dit nodig om eers 'n paar aspekte rondom die huweliksluiting en huwelikseremonies in gedagte te hou.

\subsubsection{Verlowing}

Soos elders in die Midde-Ooste het meisies en waarskynlik ook seuns, baie jonk getrou. Die ouers het dan ook al die besluite in verband met die huwelik geneem. Die twee jongmense is in baie gevalle nie eers geraadpleeg nie. Volgens Genesis 24:57 en 58 is Rebekka tog geraadpleeg of sy met Abraham se slaaf wou vertrek. As die ouers van die dogter hulle toestemming tot die huwelik gegee het, het hulle oor die voorwaardes onderhandel (De Vaux 1980:29).

Die onderhandelinge het hoofsaaklik oor die bruidsprys gegaan (Gen 29:15vv en 24:12). Dit is 'n som geld wat deur die bruidegom aan die bruid se vader betaal word. Die bruidegom kan in plaas daarvan 'n diens verrig soos Jakob (Gen 29:15-30), Otniël (Jos 5:16; Rig 1:12) en Dawid (1 Sam 18:25-27) gedoen het. Die plig om hierdie geld aan die familie van die bruid te betaal of die diens daarvoor te verrig, moet as ' $n$ vergoeding aan die familie beskou word waardeur die bruidegom 'n reg op die bruid verkry.

Die bruid word egter nie gekoop of verkoop nie, hoewel sommige uidrukkinge die indruk skep asof die bruid wel gekoop word (Gen 31:15). Die bedrag wat betaal word, wissel van geval tot geval (Baab 1981:284). Dit hang grootliks af van die bruid se vader (Gen 34:12) en van die belangrikheid van die familie (1 Sam 18:23).

Dit wil voorkom of die bruid ' $n$ reg op die bruidsprys gehad het en dit na die dood van haar vader kon erf, of daarop aanspraak kon maak as sy na die dood van haar man in geldelike nood verkeer (De Vaux 1980:32). Ragel en Lea kla byvoorbeeld teenoor Jakob: 'Ons word deur $\mathrm{Pa}$ as vreemdelinge beskou. Hy het ons verkoop en die geld opgebruik' (Gen 31:15).

Die geld waaroor ooreengekom is, word dadelik corbetaal om die verlowing te bevestig. In 1 Samuel 18:21 kom waarskynlik 'n formule voor wat deur die bruid se vader uitgespreek is om die verlowing te wettig. Tydens Dawid se verlowing met Migal sê Saul twee keer na mekaar: 'Vandag sal jy my skoonseun word'. Die huweliksbevestiging vind eers ' $n$ tyd na die verlowing plaas. 


\subsubsection{Die huwelik}

In Israel, net soos in ander lande in die ou Midde-Ooste, het die huwelikseremonie nie 'n godsdienstige karakter gehad nie. Die huwelik was 'n siviele ooreenkoms. Daar word nie in die Ou Testament melding gemaak van 'n geskrewe huwelikskontrak nie. Dat sulke dokumente wel voor die ballingskap reeds opgestel moes gewees het, kan afgelei word uit die feit dat daar in Deuteronomium 24:1-3 en Jeremia 3:8 van skeibreiwe melding gemaak word (De Vaux 1980:33).

As daar so iets soos 'n skeibrief bestaan het, kan 'n mens aflei dat daar ook 'n huwelikskontrak moes gewees het, soos daar wel onder die Jode in Elaphantine in Egipte in die vyfde eeu voor Christus voorgekom het.

In die huwelikskontrakte van Elephantine was daar 'n formule waarin die bruidegom verklaar: 'Sy is van hierdie dag af en vir altyd my vrou en ek haar man'. Die bruid het nie 'n verklaring afgelê nie (Baab 1981:285).

Die belangrikste deel van die seremonie was wanneer die bruid in die huis van die bruidegom ingaan (De Vaux 1980:33). Die bruidegom het 'n kroon gedra (Hoogl 3: 11; Jes 61:10) en vergesel van sy vriende met tamboeryne en ander musiekinstrumente na die bruid se huis opgetrek.

Die bruid was feestelik geklee en met juwele versier (Ps 45:14, 15; Jes 61:10) en het 'n sluier gedra (Hoogl 4:1, 3; 6:7) wat sy eers in die bruidsvertrek afgehaal het. Die bruid wat ook van haar vriendinne vergesel was (Ps 45:15), is dan na die huis van die bruidegom geleide gedoen (Ps 45:16; Gen 24:67). Liefdesliedere is ter ere van die bruidspaar gesing (Jer 16:9). Psalm 45 en Hooglied word deur sommige as voorbeelde van sulke liefdesliedere beskou.

Daarna is die huweliksfees gevier (Gen 29:22; Rig 14:10). Dit het gewoonlik sewe dae geduur (Gen 29:27; Rig 14:12) en is meestal by die huis van die bruidegom gehou (De Vaux 1980:34). Die bedlinne van die huweliksnag word deur die bruid as bewys van haar maagdskap bewaar as haar man haar miskien sou beskuldig dat sy nie 'n maagd was nie (Deut 22:13-21).

Die bruidegom het by die huwelik geskenke aan die bruid en haar familie gegee uit erkentlikheid vir die aanvaarding van die huweliksaanbod (Baab 1981:238). Dit is nie dieselfde as die bruidsprys nie (Gen 34:12).

Toe die onderhandelinge vir Rebekka se huwelik bevredigend afgehandel is, het Abraham se dienskneg juwele en rokke aan die bruid en geskenke aan haar ouers aangebied (Gen 24:35). Die bruid het by haar man gaan woon en, net soos haar kinders, lid van sy familie geword. 


\subsection{Egskeiding}

Huwelikke het ook soms opgebreek en dit was moontlik vir 'n man om van sy vrou te skei. Dit was egter nie 'n alledaagse verskynsel nie en daarom is teksverwysings daarna in die Ou Testament maar skraal. Die tekste wat vervolgens bespreek gaan word, is dié wat gewoonlik in die literatuur aangehaal word wanneer daar oor egskeiding geskryf word.

\subsubsection{Deuternomium 24:1-3}

Die bekendste verwysing na egskeiding in die Ou Testament, asook die teksverwysing wat die meeste aangehaal word as daar oor hierdie onderwerp geskryf word, is Deuteronomium 24:1-3.

In sy huidige vorm gaan dit in hierdie wet oor die hertrou van 'n geskeide vrou met haar eerste man, nadat sy reeds die vrou van 'n tweede man was. Volgens Mayes (1981:322) is dit ' $n$ tipiese kasuistiese wet met die protatis in vers 1 tot 3 en apodosis in vers 4.

In die wet is daar drie formele aksies wat 'n man moet neem om van sy vrou te kan skei:

* Hy moet vir haar 'n skeibrief gee,

* hy moet dit vir haar persoonlik gee, en

* hy moet sy vrou uit sy huis uit wegstuur.

As die man hierdie prosedure gevolg het, kan die man van sy vrou skei (Mayes 1981: 322).

Die rede vir egskeiding in hierdie teks word gegee as 'iets onbetaamliks' wat die man in die vrou sou vind. Wat die 'iets onbetaamliks' is, weet niemand meer presies nie. Dit kon egter nie owerspel gewees het nie, want daarvoor was die straf die dood en nie net 'n egskeiding nie (Lev 20:10-12). Dit moes ook iets anders as agterdog en 'n vermoede van owerspel gewees het want daarvoor was daar volgens Numeri 5:11-31 ook 'n ander voorskrif.

Die vraag ontstaan waarom die eerste man die vrou nie mag terugneem nie? Die antwoord hou verband met die eerbaarheid van die huwelik. Wanneer die man haar terugneem, word die sonde van egbreek wat reeds met die eerste wegstuur plaasgevind het en ook deur die tweede man gepleeg is, voortgesit. Dit gaan dus om die eerbaarheid van die huwelik en die saak van die huwelik wat in beskerming geneem moet word. 
Die huwelik is nie iets waarmee ligtelik omgegaan kan word sonder om aan die gevolge daarvan gebonde te wees nie. Jy kan nie maar skei en gerieflikheidshalwe weer trou en dit wat daartussen gebeur (die vrou wat intussen met 'n ander man getroud was), ignoreer nie.

Deuteronomium 24 wil nie die feit van egskeiding wettig nie. Dit dui wel aan dat so 'n prosedure binne die Joodse gemeenskap bestaan het. Die bedoeling van egskeiding binne die sosiale orde van die Israelitiese gemeenskap was om in 'n sondige situasie verdere verwarring te voorkom en om die heiligheid van die huwelik te beskerm.. Die egskeidingsbrief het voorkom dat sy aan willekeurige mishandeling en wreedheid blootgestel is. Dit het ook aan haar die geleentheid gebied om weer te kon trou.

\subsubsection{Samuel 3:14-16}

Levitikus 22:13 bepaal dat 'n verstote vrou weer in haar vader se huis opgeneem moet word. Dit was waarskynlik die geval met Mikal toe Dawid vir Saul gevlug het. Hulle is egter nooit formeel geskei nie (Taber 1984:245).

Saul het haar egter aan ' $n$ ander man gegee, maar Dawid het haar teruggevat. Dit was nie teenstrydig met Deuteronomium 24:1-4 nie omdat Dawid nooit wettig van haar geskei was nie (De Vaux 1980:35).

\subsubsection{Rigters 15:1-6}

Na die bedrog met sy raaisel het Simson kwaad geword en na sy pa se huis toe teruggegaan. Toe hy later weer sy vrou gaan opsoek, het haar pa haar aan 'n ander man gegee. Volgens die gewoontereg het ons hier blykbaar te doen met omstandighede waar die optrede van die man tot 'n situasie kon lei waarin die huwelik as ontbind beskou kan word (Oberholzer 1981:196).

\subsubsection{Jeremia 3:1-5}

Die uitspraak in Deuteronomium 24:1-4 het 'n parallel in Jeremia 3:1-5. Jeremia 3:1-5 is in die vorm van ' $n$ retoriese vraag en die antwoord is in Deuteronomium 24:1-4 (Carrol 1986:143). Volgens Van Selms (1980:60) maak die wet dit vir 'n man onmoontlik om ' $n$ vrou terug te vat wat intussen met ' $n$ ander man getroud was en met hom gemeenskap gehad het.

Die teks in Jeremia 3:1-5 praat egter nie per se oor egskeiding of die huwelik nie. Dit is volgens Carrol (1986:143) 'n metafoor wat die verhouding tussen JHWH en Israel teken. Dit wil sê: wat by mense onmoontlik is, is moontlik by God want Hy roep Israel op tot bekering en $\mathrm{Hy}$ is bereid om hulle terug te vat. 


\subsubsection{Hosea 2:1}

In Hosea 2:1 word die beeld van die huwelik weer gebruik om die verhouding tussen $J H W H$ en Israel mee aan te dui. Die woorde 'Sy is nie meer my vrou nie, Ek is nie meer haar man nie', is volgens Van Leeuwen (1984:53) 'n tipiese egskeidingsformule wat uit Akkadies ontleen is. In Israel was die blote uitspreek van 'n formule nie genoeg nie. Vir 'n egskeiding is daar 'n formele skeibrief benodig (Deut 24:1, 3; Jes $50: 1 ;$ Jer 3:8).

Hierdie formule word nie hier gebruik as 'n skeiformule om die verhouding tussen $J H W H$ en Israel mee te beëindig nie, 'zij constateren veeleer met leedwezen, dat de moeder door haar gedrag het huwelijk in feite verbroken heeft, en het haar man onmogelijk heeft gemaakt nog langer haar man te zijn' (Van Leeuwen 1984:53).

\subsubsection{Maleagi 2:16}

Baie kommentatore het Maleagi 2:10-16 in die verlede uitgelê asof dit 'n negatiewe oordeel oor egskeiding is (Peterson 1995:205). Om dit te doen, is volgens Swanepoel (1995:73) om vanuit die sekondêre betekenisvlak te praat.

Die hele teks is 'n profetiese rede. Hierdie sin moet teen daardie agtergrond en in daardie konteks gelees word (Lescow 1993:101). Soos wat dit die geval is met Hosea en Jeremia, word huweliks- en egskeidingsbeelde gebruik om metafories die verhouding tussen $J H W H$ en Israel te teken (Peterson 1995:205).

Dit gaan dus primêr in die teks oor ontrou teenoor God. Die egskeidingsituasie word as verwysingsraamwerk gebruik om Israel se verbondsontrou mee aan te spreek: Soos in 'n ontroue huwelik, dwaal die mense af en kom hulle in aanraking met ander godsdienste wie se afgode meer aantreklik lyk as diens aan die Here God (Swanepoel 1995:73).

\subsubsection{Ander teksverwysings}

Afgesien van Deuteronomium 24:1 se rede vir egskeiding, lyk dit volgens Esra 10:3 en 44 asof mens ook op grond van godsdienstige redes kon skei. Die Bybel noem ook redes wat onaanvaarbaar was vir egskeiding. As 'n man byvoorbeeld van sy vrou geskei het deur haar valslik te beskuldig dat sy nie 'n maagd was toe hulle getroud is nie, moes hy haar teruggevat het (Deut 22:19) indien die ouers die bewyse daarvoor kon verskaf in die vorm van 'n bloedbevlekte doek (Tabar 1984:244). Die man is beboet met 'n honderd shekels, 'n drag slae, en hy is verbied om ooit van sy vrou te skei. As die ouers egter nie haar maagdelikheid kon bewys nie, moes sy gestenig word (Deut 22:13-21). 
In geval waar 'n man 'n vermoede van owerspel van sy vrou gehad het, maar hy kon dit nie bewys nie, het die vrou 'n verhoor (Num 5:11-31) gehad waarin sy ondervra en getoets is. As sy skuldig bevind is, is sy verwerp. 'n Man wat met 'n meisie moes trou omdat hy haar verkrag het, kon ook nie van haar skei nie (Deut 22:29). Volgens Baab (1982:859) kon 'n man ook nie, as hy 'n slaaf as tweede vrou geneem het, van die eerste skei nie.

\subsubsection{Opsomming}

Uit die Ou-Testamentiese gegewens is dit duidelik dat die huwelik hoog geag is en dat dit beskerm moes word. Dit het die huisgesin en die familienaam beskerm, en dit was belangrik in die daarstelling van 'n nageslag. Egskeiding was onaanvaarbaar. In gevalle waar dit egter wel voorgekom het, was daar duidelike riglyne en voorskrifte oor hoe dit hanteer moes word en wat die toelaatbare redes daarvoor was.

\section{ANDER SEMITIESE LITERATUUR}

\subsection{Aramese huweliksdokumente te Elephantine}

Volgens die huwelikskontrakte wat deur die Joodse kolonie te Elephantine gebruik is, is daar volgens Yaron (1958:11) sekere voorwaardes wat betrekking het op 'n egskeiding.

\subsubsection{Formele egskeiding}

Dit word verkry deur die uitspreek van sekere formules. 'n Formele egskeiding is in 'n sekere sin beter as ' $n$ informele egskeiding omdat dit meer duidelikheid oor die posisie van die vrou gee.

'n Formele egskeiding is verkry deur die uitspreek van 'n formule: 'Ek skei van $\mathrm{x}$ my vrou, sy sal nie meer my vrou wees nie'. En as die inisiatief van die vrou se kant af kom, het sy gesê: 'Ek skei van $x$ my man, en sal nie meer vir hom 'n vrou wees nie' (De Vaux 1980:35).

Al praat Deuteronomium 24:1 van 'n skeibrief, word daar geen melding van so 'n dokument in die Aramese papiri gemaak nie. Volgens Yaron (1958:16) was dit waarskynlik nie die gebruik te Elephantine om 'n skriftelike skeibrief uit te reik nie. As die regte formule net voor getuies uitgespreek is, was dit voldoene.

Die party wat die inisiatief geneem het om te skei, was verplig om die egskeidingsgelde ( $k s p s n$ ' $h$ ) te betaal. Die bedrag het verskil afhangende of dit die man of die vrou is wat die inisiatief tot die egskeiding geneem het. 
Gewoonlik moes die man net die aanvanklike bruidsprys weer terugbetaal. Dit het egter gewissel van geval tot geval. Die $k s p s n$ 'h wat die vrou aan die man moes betaal in gevalle waar die inisiatief vir die egskeiding van haar afkom, was altyd so ongeveer sewe en 'n half shekels (Ýaron 1958:17). Volgens De Vaux (1980:35) kon die man nooit die mohar terugeis nie. Na die egskeiding kon die vrou haar persoonlike eiendom met haar saamneem. Daar is egter ook gevalle bekend waar nie die man of die vrou onderhoud of $k s p s n$ 'h moes betaal nie, maar waar elkeen net weer dit uit die huwelik geneem het wat hulle ingebring het (Yaron 1958:19).

\subsubsection{Die uitsit van die vrou}

Om 'n vrou bloct uit die man se huis te sit, het nie die huwelik ontbind nie. Volgens (Yaron 1958:11) kon so 'n man 'n groot boete kry. Hy kon dan ook verplig geword het om die vrou behoorlik te skei.

\subsubsection{Agtergrond van die wette}

Die huwelikswette te Elephantine is 'n mengsel van Oosterse en Egiptiese wette. Die huweliksluitings- en egskeidingsformules is Oosters. So ook die betaling van die mohar aan die hoof van die bruid se familie. Die Egiptiese invloed is weer te sien in die ontstaan van 'n skriftelike huwelikskontrak, die vrou se reg om van haar man te skei, die vrou se reg tot haar man se eiendom, en die buigbare hantering in die wet met betrekking tot 'n vrou wat owerspel gepleeg het of wat wil hertrou (Yaron 1958:36).

\subsection{Ugarit}

In Ugarit kon die pa van die bruid 'n mondelinge kontrak met die voornemende bruidegom opstel waardeur die bruidegom verplig word om net een vrou te hê. As hy dus 'n tweede vrou geneem het, is hy outomaties van sy eerste vrou geskei en is hy verantwoordelik gehou vir haar onderhoud. Hy kon ook 'n swaar boete opgelê word wat hy aan haar ouers of aan die koning van Ugarit moes corbetaal (Van Selms 1954:21).

Die pa van die bruid het op haar troudag aan haar 'n groot geskenk gegee. Vir solank as wat die man met haar getroud was. het hy vruggebruik van die geskenk gehad. Die oomblik as hulle sou skei, moes hy alles aan haar terugbetaal (Van Selms 1954:33).

Volgens Van Selms (1954:49) het daar in Ugarit geen geskrewe huwelikskontrakte bestaan nie. Die daad waarmee ' $n$ vrou in 'n man se huis ingebring is en afgesny is van haar familie, het dieselfde funksie vervul as die sluiting van ' $n$ huwelikskontrak. Net so was dit ook wanneer 'n man sy vrou sou terugneemı na haar vader se huis toe en haar daar los. Die daad is geïnterpreteer as 'n egskeiding en die daad het gegeld in die plek van 'n geskrewe egskeidingsdokument. 


\subsection{Kodeks Hammurapi, Assiriese Wetboek en die Hetitiese Kodeks}

Wanneer daar na die bure van Israel gekyk word, toon die Assiriese wette 'n beskawing aan wat omtrent aan barbarisme grens. Die Hetiete is minder wreed. Die Kodeks van Hammurapi weerspieël 'n hoër staat van ontwikkeling en volwassenheid (Paterson 1932:161).

Volgens die Assiriese wet kon 'n man van sy vrou skei op grond van haar beledigende en lasterlike praatjies en oor haar skoorsoekerige persoonlikheid. Die man moes net sê: 'Ek verwerp jou' of 'Jy is nie meer langer my vrou nie', dan was hulle geskei (De Vaux 1980:35).

Die Kodeks Hammurapi lê die willekeurige reg van die man effens aan bande deur daarvoor voorsiening te maak dat hy die bruidskap moet terugbetaal en dat hy verantwoordelik is om onderhoud te betaal. As 'n vrou onvrugbaar was, kon haar man van haar skei, maar in so 'n geval moes hy die bruidsprys, sowel as die bruidskat terugbetaal (De Vaux 1980:35). Die Kodeks Hammurapi het die vrou se skuld of onskuld in berekening gebring wanneer die egskeidingsgelde bepaal is. As sy skuld het aan die egskeiding, kon die man haar met leë hande wegstuur of hy kon haar tot die posisie van 'n slaaf verlaag. As die vrou egter onskuldig is, kon sy haar bruidskat neem en teruggaan na haar vader se huis. Hierdie toegewing word gekwalifiseer met die bepaling dat as sy nie 'n goeie vrou was nie en as sy haar huishouding verwaarloos het, kon sy in die rivier gegooi word (Paterson 1932:163).

Kroniese siekte was volgens die wet nie 'n rede vir egskeiding nie. Die man kon dus nie sy plig teenoor sy siek vrou nalaat nie. Tog is hy volgens Paterson (1932:163) in so 'n geval toegelaat om vir hom 'n tweede vrou aan te skaf.

In die Hetitiese Kodeks word daar geen melding gemaak van die man se reg om te skei nie. Omdat dit so algemeen aanvaar was, was dit nie nodig om dit in 'n wet in te skryf nie. Die Hetitiese Kodeks laat egskeiding toe op grond van wedersydse instemming met die voorwaarde dat die bruidsprys terugbetaal word (Paterson 1932:164).

Volgens die Kodeks Hammurapi was die vrou, wat deur haar man verlaat is, vry om weer te trou. As die verlating onopsetlik was, soos byvoorbeeld wanneer die man tydens 'n oorlog as 'n gevangene geneem is, was die vraag volgens die wet na die onderhoud en instandhouding van die vrou en die huishouding gedurende die man se afwesigheid. As daar vir haar versorging was, moes sy wag totdat haar man terugkeer. As sy nie gewag het nie, moes sy in die rivier gegooi word. As daar geen versorging vir haar was nie, kon sy met ' $n$ ander man trou. As haar man egter later terugkeer kon hy haar weer opeis. Die kinders wat sy dalk in die tussentyd by die ander man gehad het, kon dan by hom agterbly (Paterson 1932:167). 
Volgens die Assiriese wette kon so 'n vrou nie hertrou nie. As sy kinders gehad het, moes hulle werk en haar versorg tydens haar man se afwesigheid. As sy nie kinders gehad het nie, moes sy vyf jaar gewag het voordat die huwelik ontbind kon word en dan het die man ook geen aanspraak meer op haar gehad indien hy sou terugkom nie. In so 'n geval kon sy ook weer hertrou. As die man egter kon bewys dat hy vir vyf jaar of langer in gevangenisskap was, kon hy aanspraak maak op sy vrou en kon hy haar terugkry, al is sy intussen weer getroud. In so 'n geval moes hy net aan die man met wie sy vrou getroud is, 'n plaasvervanger voorsien. As die vrou hertrou voordat die vyf jaar om is, kon haar man op haar en op enige kinders wat sy intussen gekry het, aanspraak maak omdat sy nie vir die voorgeskrewe tyd gewag het nie.

As die vrou egter nie 'n skoonpa of kinders gehad het nie, was die wagperiode nie vyf jaar nie, maar twee. Ook in hierdie geval kon die man sy vrou weer opeis ongeag van die tydperk wat hy weg was.

Volgens die Assiriese wet kon 'n man van sy vrou skei sonder enige vorm van kompensasie. Die vrou se ouers kon egter haar belange beskerm deur voor die huwelik sekere klousules in 'n kontrak in te skryf (De Vaux 1980:35).

\subsection{Babiloniese Wette}

In kulture waar poligamie 'n algemene gebruik was, kon 'n vrou nie haar man se poligamie as 'n grond vir egskeiding aanbied nie, terwyl dit wel 'n aanvaarbare rede was in gemeenskappe waar poligamie nie so algemeen was nie. Die gebruik in Babilonië was byvoorbeeld dat 'n man soveel vrouens kon neem as wat hy wou. Hy moes net in staat wees om vir hulle almal te sorg.

'n Byvrou het volgens Epstein (1942:41) in plaas van huweliksgeskenke die versekering ontvang dat sy 'n sekere bedrag as egskeidingsprys sou ontvang as haar huwelik sou ontbind. Die prosedure om van 'n byvrou ontslae te raak, was dieselfde as vir 'n egskeiding. By die Israeliete was dit anders. 'n Byvrou het nie 'n egskeidingsbrief gekry nie. Sy is bloot uit die huis weggestuur (Epstein 1942:53).

By die dood van 'n Babiloniese patriarg kon die byvroue oorgedra word aan sy opvolger, of hulle kon vrygelaat word om met die man van hulle keuse te trou (Epstein 1942:42).

\subsection{Apokriewe boeke}

Volgens die apokriewe boek 'Die wysheid van Jesus die seun van Sirag' (25:26) kon 'n man van sy vrou skei as sy nie aan haar man gehoorsaam was nie. 


\section{JOODS-GODSDIENSTIGE GESKRIFTE}

\subsection{Talmud}

Volgens die Talmud was daar vier tipes egskeiding:

* 'n Egskeiding deur wedersydse toestemming - in so 'n geval het die vrou haar kethubah ontvang.

* 'n Egskeiding deur die man wanneer die vrou die skuldige party is - in so 'n geval het sy die kethubah verloor.

* 'n Egskeiding op versoek van die vrou wanneer die man die skuldige party is.

* 'n Egskeiding deur die hof self, selfs sonder die aansoek van een van die partye (Paterson 1932:165).

Die vrou kon nooit aan haar man 'n egskeidingsbrief gee nie, maar sy kon hom wel deur die hof forseer het om een aan haar te gee. Tussen Eksodus 21:10 en 11 en die Talmudiese periode het daar volgens Paterson (1932:165) 'n geweldige ontwikkeling plaasgevind want die Talmud noem sewe gronde waarop 'n man van sy vrou kan skei.

In Palestina (volgens Talmud Yeb 65a) waar poligamie minder algemeen was, is bepaal dat poligamie wel rede vir ' $n$ egskeiding kan wees. As ' $n$ vrou beswaar maak teen haar man se voorneme om nog 'n vrou vir hom te neem, kan dit as 'n wettige rede vir egskeiding dien. Poligamie is sowel in Bybelse as in Talmudiese tye nie angemoedig nie. Volgens Epstein (1942:21) het Rabbi 'Ammi selfs in die na-Talmudiese tyd poligamie as 'n wettige rede vir egskeiding aanvaar.

Oor 'n vrou wat onopsetlik deur haar man verlaat is, soos byvoorbeeld as hy gedurende 'n oorlog as gevangene weggeneem word, berig die Talmud soos volg (Paterson 1932:168): Hierdie vrou kon nie hertrou voordat haar man nie eers dood is, of voordat sy wettig van hom geskei is nie. Sy dood in gevangenisskap moes ook eers bewys word voordat die vrou kon hertrou. Een getuie wat sy dood bevestig het, in plaas van die gebruiklike twee getuies was genoeg.

Rabbi 'Ammi maak in die Talmud ook 'n saak daarvoor uit dat 'n man in 'n kinderlose huwelik, wat sy vrugbaarheid wil bewys, van sy eerste vrou mag skei, aan haar die kethubah betaal en dan ' $n$ tweede vrou neem en by haar kinders verwek (Lowy 1958:121). Die vrou mag volgens rabbi 'Ammi nie op grond van haar kinderloosheid aanspraak op 'n egskeiding en haar kethubah maak nie, omdat die opdrag 'om vrugbaar te wees en te vermeerder' nie aan haar gegee word nie maar aan die man. Dieselfde 
opinie word ook deur die Halakhah gehuldig. Die vrou het as gevolg van haar kinderloosheid geen reg om aanspraak op haar kethubah te maak nie (Lowy 1958:121).

Rabbi Judah voeg hierby dat as sy vra vir 'n egskeiding omdat sy met iemand anders wil trou, sy wel die reg het om dit te doen, maar in so 'n geval mag sy nie aanspraak maak op haar kethubah nie. Die Tosefta maak egter die uitspraak dat sy mag skei en dat die man wel die kethubah moet betaal. Die Babiloniese wette het 'n man verplig om van sy vrou te skei as hulle na tien jaar steeds kinderloos was (Lowy 1958:122).

\subsection{Mishna}

Die Mishna se uitsprake konsentreer nie op die instelling van die egskeiding nie, maar op die detail en inhoud van die skeibrief en oor die prosedure oor hoe om dit geskryf en afgelewer te kry. Die oorsprong van die woord get is onseker.

Dit word volgens Lipman (1970:185) slegs gebruik om twee soorte dokumente mee an te dui:

* die dokument wat benodig word vir 'n egskeiding en

* die dokument waarmee slawe vrygemaak word. In die meeste gevalle word daarmee egter 'n 'skeibrief' bedoel.

Die egskeidingsprosedure was baie duidelik: die man moes die skeibrief opstel en hy moes dit op een of ander manier aan die vrou oorhandig. Hierdie prosedure maak die grootste gedeelte van die Mishna-traktaat uit.

Afgesien van die twee redes wat daar in Deuteronomium 22 gegee word op grond waarvan 'n man nie van sy vrou mag skei nie, voeg die Mishna nog drie by (Paterson 1932:163). Hy mag nie van haar skei as sy (a) waansinnig is nie (Yebamoth 14:1); (b) as sy in gevangenisskap is nie, want dan is dit eerder sy plig om haar vry te koop (Kethuboth 4:1); en (c) wanneer sy minderjarig is (Gittin 6:2).

Die teks in die Mishna in verband met egskeiding wat die meeste aangehaal word, is Gittin 9:10. Dit is geskryf as kommentaar op Deuteronomium 24:1. 'n Man kon van sy vrou skei as hy iets onbetaamliks aan haar gevind het. Hierdie uitdrukking is baie vaag. Joodse geleerdes het hierdie vers op verskillende wyses geïnterpreteer. Die rigoristiese skool van Shammai het geglo dat daar met 'onbetaamlik' verwys word na egbreuk of seksuele wangedrag (De Vaux 1980:34). Die meer liberale skool van Hillel het omtrent enige rede aanvaar. So byvoorbeeld kon 'n man van sy vrou skei as sy die kos nie goed voorberei het nie (Baab 1982:859). Rabbi Akiba het gesê dat 'n man van sy vrou kon skei selfs as hy net 'n mooier vrou as sy eie gesien het (Lipman 1970:189). 
Die Gittin, is die traktaat in die Mishna wat oor egskeiding handel. Dit bestaan uit nege hoofstukke. Hammelburg (1987:573) het 'n kort opsomming van die inhoud van elke hoofstuk gemaak. In hoofstuk een gaan dit oor skeibriewe wat van 'n ander plek/ dorp na die vrou toe gebring word; die betroubaarheid daarvan en die terugtrek van die bevel om die skeibrief te oorhandig. Hoofstuk twee bepaal waarmee, waarop en deur wie die skeibrief geskryf mag word en wie betroubaar is om die brief af te lewer. Hoofstuk drie hanteer die formele inhoud van die skeibrief asook sake soos 'n skeibrief wat verlore geraak het en toe weer later gevind is. Hoofstuk vier handel oor die vraag hoe ' $n$ egskeiding voorkom kan word nadat die skeibrief reeds uitgestuur is. Hoofstuk vyf spreek die onderlinge goeie verstandhouding aan terwyl hoofstuk ses die praktiese reëlings rondom die skryf, oorhandiging en in ontvangs neem van die skeibrief hanteer. Hoofstuk sewe hanteer die situasie wanneer 'n siek man 'n skeibrief wil skryf of onderteken, asook die reëlings rondom 'n voorwaardelike egskeiding. Hoofstuk agt bespreek die verkeerde datering van 'n skeibrief asook ongeoorloofde huwelike. Hoofstuk nege hanteer die voorwaardes van 'n egskeiding, onvoldoene handtekeninge, die geloofwaardigheid van die gerugte omtrent die vrou en die redes tot 'n egskeiding.

Wanneer die Mishna kommentaar lewer op Deuteronnmium 24:1-5, word daar gesê dat 'n man nie sy vrou mag terugneem nadat hy van haar geskei is as sy in die tussentyd weer getroud is nie, op grond van die volgende redes:

* as die vrou geskei is op grond van 'n vermoede dat sy owerspel gepleeg het;

* as hulle geskei is omdat die vrou sekere huweliksbeloftes nie nagekom het nie;

* as die vrou geskei is op grond van haar onvrugbaarheid; en

* as 'n derde party die afkoopbedrag van die kethubah gewaarborg het (Paterson 1932:166).

\section{Opsomming}

$\mathrm{Al}$ die sekondêre bronne wat hierbo bespreek is, ondersteun in ' $\mathrm{n}$ mindere of meerdere mate die Ou Testamentiese beskouing oor die huwelik. Die volgende algemene afleidings sou gemaak kon word: die huwelik is as ' $n$ instelling geken en gerespekteer; Egskeiding was die uitsondering, nie die reël nie; Egskeiding het wel voorgekom; Daar was egter duidelike gebruike, riglyne en voorskrifte oor hoe dit hanteer moes word. 


\section{Gevolgtrekking}

Huwelike kon en het dus ook soms opgebreek en dit was van die vroegste tye af moontlik vir iemand om van sy vrou te skei. Egskeiding is egter nie iets wat dikwels in Israel voorgekom het nie (Taber 1984:245). Aangesien die familie-eenheid so belangrik was, is die stabiliteit van die gesin beskerm en is die getrouheid van beide egliede hoog waardeer (vgl Spr 6:20-35). In die gevalle waar 'n huwelik wel deur 'n egskeiding beëindig is, was daar altyd ' $n$ vorm van kompensasie. In gevalle waar die inisiatief vir die egskeiding van die man se kant af gekom het, is die vrou deur die wet beskerm en het sy onderhoud ontvang.

\section{Literatuurlys}

Baab, O J 1981. Marriage. IDB Vol 3, 279-286.

1982. Adultery. IDB Vol 1, 51.

1982. Divorce. IDB Vol 1, 859.

Cassuto, U 1967. A Commentary on the book of Exodus. Jerusalem: The Magnes Press.

Carrol, R P 1986. Jeremia. London: SCM Press.

De Vaux R 1980. Ancient Israel: Its life and Institutions. London: Darton Longman and Todd.

Epstein, L M 1942. Marriage Laws in the Bible and the Talmud. New York: Johnson Reprint Corporation.

Fensham, F C 1984. Exodus. Nijkerk: G F Callenbach.

Hammelburg, S 1987. De Misjna, Deel III - Séder nasjiem. Amsterdam: N.I.K.

Kornfeld, W 1980. Levitikus. Stuttgart: Echter Verlag.

Tescow, 1993. Das Buch Maleachi. Stuttgart: Calwer Verlag.

Lipman, E J 1970. The Mishnah. New York: The Viking Press.

Lowry, S 1958. The Extent of Jewish Polygamy in Talmudic Times. JSS 9, 115-38.

Mayes, A D H 1981. Deuteronomy. Grand Rapids: W B Eerdmans.

Oberholzer, J P 1981. Bybelse Oudheidkunde, in Fensham, F C \& Oberholzer, J P, Bybelse Aardrykskunde, Oudheidkunde en Opgrawings, 119-307. Pretoria: Interkerklike Uitgewerstrust.

Paterson, J 1932. Divorce and Desertion in the Old Testament. JBL 60, 161-70.

Petersen, D L 1995. Zechariah 9-14 and Malachi. Kentucky: Westminster John Knox Press.

Swanepoel, M G 1995. Om die hatende weg te stuur of egskeiding te haat: Watter een wil die Here nie in Maleagi 2:13-16?, NGTT 36/1, 65-74. 
Taber, C R 1984. Divorce. IDB Suppl Vol, 244-245.

Van Leeuwen, C 1984. Hosea. Nijkerk. G F Callenbach.

Van Selms, A 1980. Jeremia, deel 1. Nijkerk: G F Callenbach.

1954. Marriage and Family life in Ugaritic Literature. London: Luzac and Company, Ltd.

Yaron, R 1958. Aramaic Marriage Contracts from Elephantine. JSS 3/1, 1-39. 1960. Aramaic Marriage Contracts: Corrigenda and Addenda. JSS 5, 66-70. 